\title{
The Role of Athletic Self-efficacy and Athletic Perfectionism in Predicting Athletic Performance of Gazi University Student Athletes
}

\author{
Temel Çakiroğlu (Corresponding author) \\ Department of Sport Science, Lokman Hekim University, Ankara, Turkey \\ E-mail: temel.cakiroglu@lokmanhekim.edu.tr
}

Received: October 18, $2021 \quad$ Accepted: November 17, 2021

Published: December 1, 2021

doi:10.5296/jei.v7i2.19108 URL: https://doi.org/10.5296/jei.v7i2.19108

\begin{abstract}
Athletic performance is the physical and mental effort of an individual or a sports team to win and defeat the other person or team. The aim of this study was to investigate the role of athletic self-efficacy and athletic perfectionism in predicting athletic performance of athletic students of Gazi University.

The method of this study is descriptive and correlational. The statistical population includes all student athletes of Gazi University, which is 360 people. To determine the sample size, Cochran's sample size estimation formula was used and the number of samples was equivalent to 186 individuals selected by simple random sampling method. Standard questionnaires on athletic self-efficacy, athletic perfectionism and athletic performance were used to collect data. The data were analyzed using SPSS 24 software. Descriptive statistics for quantitative variables were presented as mean and standard deviation. The regression coefficient was used to determine the role of athletic self-efficacy and perfectionism in predicting students' athletic performance.

Athletic self-efficacy and athletic perfectionism play an important role in predicting athletic performance of student athletes. Athletic self-efficacy and athletic perfectionism predicted 0.54 and $0.46(p<0.05)$ of changes in athletic performance, respectively.

As athletic self-efficacy and athletic perfectionism increase, so does athletic performance in student athletes. Coaches are advised to pay attention not only to physical condition but also to psychological characteristics and especially to indicators of perfectionism and self-efficacy when selecting players.
\end{abstract}


Keywords: Athletic self-efficacy, Athletic perfectionism, Athletic performance

\section{Introduction}

A healthy society requires effort and physical activity. The physical and mental effort made by an individual, a group or a sports team to achieve a certain goal can be called athletic performance. This is a definition of athletic performance that encompasses any athletic activity. In other words, it is used for professional athletes as well as people who train for their physical health. The definition of athletic performance in its specific meaning means the physical and mental effort of a person or a sports team that is done in sports competitions with the intention of winning and defeating the other person or team (Rostamzadeh \& Zehsaz, 2020).

Considering the status of sports competitions in international arenas, it is clear that the role of psychological factors in athletic performance is very important and significant (Roberts, 2001). They also achieve significant success, both in international competitive arenas and in improving the health of the sport community. Today, sport psychologists have studied the effects of sport on various psychological variables as well as the effects of these variables on athletic performance. This study examined the role of athletic self-efficacy and perfectionism in predicting athletic performance.

In the last few decades, sport psychology has become an important part of sport, as well-informed and experienced before the competition and during training and exercises try to achieve a level of self-confidence, self-efficacy and measure relevance of these factors to the athlete's success and failure. One of the applications of psychology in sport is to help improve performance, to learn and to execute more correctly and more easily the skills, using different techniques such as mental training, self-confidence and self-efficacy. Admittedly, these psychosocial skills are the main and most prominent components of continuous performance at high levels of competition (Newland et al., 2013).

Athletic self-efficacy essentially means feeling competent and able to deal with the problems that arise in athletic competition. Athletic self-efficacy is defined as the athlete's belief in the ability to perform a successful operation to achieve a specific outcome in athletic performance. On the one hand, athletic self-efficacy includes the athlete's abilities, physical and mental fitness, leadership and coaching, and situational superiority, and on the other hand, it influences the athletic performance, success, and the ability to cope with stress (Sivrikaya, 2019).

The second factor that is influential for performance is perfectionism. Several chapters (e.g., Jowett, Mallinson, \& Hill, 2016) and review articles (e.g., Hill \& Madigan, 2017) have recently been published that are focused on the consequences of perfectionism.

Madigan et al (2018) also concluded in their study that perfectionism improves athletic performance. Therefore, it can be inferred that one of the most important psychological factors related to people's athletic performance is their perfectionism. Perfectionism is a multidimensional personality trait characterized by the pursuit of flawlessness, setting high standards of performance, and a hypercritical evaluation of one's behavior (Madigan et al., 
2016).

Stoeber (2014) introduces two positive and negative dimensions for perfectionism and believes that in positive perfectionism, people are motivated with the goal of success and can accept personal and social limitations while emphasizing the criteria of a high performance plan. This dimension of perfectionism leads to the development of skills and talents and has characteristics such as strong motivation and a desire for self-actualization (Stoeber, 2014).

Perfectionism are most commonly measured using instruments that capture high personal standards, self-oriented perfectionism (imposing the need for perfection on the self), and striving for perfection (Stoeber \& Madigan, 2016).

According to Gallucci (2008), perfectionism in athletes has a largely healthy structure. In this mechanism, athletes shift their focus from aggressive behavior and anger to perseverance and effort, and pay less attention to the troubling aspects in order to better understand the logical dimensions of sports situations. Perfectionistic efforts to set very high personal performance standards are largely consistent with athletes (Gotwals et al., 2012). Since athletic performance is strongly influenced by psychological variables and due to the research gap in this area and the importance of perfectionism and self-efficacy in predicting athletic performance, the present study aims to answer the question of the role of athletic self-efficacy and athletic perfectionism in predicting athletic performance of athletic students at Gazi University.

\section{Method}

The method of this study is descriptive and correlational. The statistical population includes all student athletes of Gazi University, which is 360 people. To determine the sample size, Cochran's sample size estimation formula was used and the number of samples was 186 people who were selected by simple random sampling method. Standard questionnaires were used to collect the information.

The Athletic Self-Efficacy Questionnaire was created and validated by Sahraian et al. (2016). The final version of this questionnaire includes 22 items. The questionnaire is scored on a 5-point Likert scale (very low to very high) from 1 to 5 points. The validity of the main parts of the questionnaire was checked and confirmed by Sahraian et al. (2016). Moreover, its reliability was reported with a Cronbach's alpha coefficient of 0.97 and split-half method of 0.94 .

The Athletic Perfectionism Questionnaire was developed and validated by Dunn et al. (2006). The final version of this questionnaire includes 42 items. This instrument is scored on a 5-point Likert scale (strongly disagree to strongly agree) from 1 to 5 points. The validity of the main sections of the questionnaire was tested and confirmed by Dunn et al. (2006). Its reliability was also reported with a Cronbach's alpha coefficient of 0.89 .

The Athletic Performance Questionnaire was developed and validated by Charbonneau et al. (2001). The final version of this instrument includes 5 items. The instrument is scored on a 5-point Likert scale (poor to excellent) ranging from 1 to 5 . The validity of the main sections 


\section{Macrothink}

of the questionnaire was checked and confirmed by Charbonneau et al. (2001). The reliability of the questionnaire was also reported with a Cronbach's alpha coefficient of 0.85 .

Data were analyzed using SPSS software version 24. Descriptive statistics for quantitative variables were presented as mean and standard deviation. A regression coefficient was used to determine the role of athletic self-efficacy and perfectionism in predicting students' athletic performance.

\section{Results}

Table 1. Average and standard deviation of athletic self-efficacy, athletic perfectionism and athletic performance

\begin{tabular}{|l|l|l|}
\hline Variable & Mean & Standard deviation \\
\hline Athletic self-efficacy & 77.94 & 9.76 \\
\hline Athletic perfectionism & 139.61 & 21.96 \\
\hline Athletic performance & 19.23 & 2.55 \\
\hline
\end{tabular}

According to the results of the Table 1, the mean of athletic self-efficacy is $77.94 \pm 9.76$, athletic perfectionism is $139.61 \pm 21.96$, and athletic performance is $19.23 \pm 2.55$.

Table 2. Summary of regression model: the effect of athletic self-efficacy on athletic performance

\begin{tabular}{|l|l|l|}
\hline Adjusted R Square & R Square & R \\
\hline 0.298 & 0.302 & 0.549 \\
\hline
\end{tabular}

According to the results of Table 2, the correlation coefficient between athletic self-efficacy and athletic performance is 0.54 and the coefficient of determination is 0.30 . In other words, 0.30 of the changes in athletic performance are determined by athletic self-efficacy and 0.70 by other variables. 


\section{1) Macrothink}

Table 3. The results of the simple regression equation: effect of athletic self-efficacy on athletic performance

\begin{tabular}{|l|l|l|l|l|l|l|}
\hline \multirow{2}{*}{ Model } & \multicolumn{2}{|l|}{ Unstandardized Coefficients } & Standardized Coefficients & & \multirow{2}{*}{$\mathrm{t}$} \\
\cline { 2 - 6 } & $\mathrm{B}$ & Std. Error & Beta \\
\hline \multirow{2}{*}{1} & (Constant) & 51.26 & 6.50 & & 7.88 & 0.001 \\
\cline { 2 - 6 } & Athletic self-efficacy & 0.74 & 0.08 & 0.54 & 8.91 & 0.001 \\
\hline
\end{tabular}

According to the results of Table 3 and considering the significant test error level for the confidence level of 0.95 , it can be said that athletic self-efficacy has a significant positive effect on athletic performance. The beta coefficient also shows that athletic self-efficacy predicts 0.54 of the changes in athletic performance.

Table 4. Summary of regression model: the effect of athletic perfectionism on athletic performance

\begin{tabular}{|l|l|l|}
\hline Adjusted R Square & R Square & R \\
\hline 0.213 & 0.218 & 0.467 \\
\hline
\end{tabular}

According to the results of Table 4, the correlation coefficient between athletic perfectionism and athletic performance is 0.46 and the coefficient of determination is 0.21 . In other words, it can be said that 0.21 of the changes in athletic performance are determined by athletic perfectionism and 0.79 are determined by other variables.

Table 5. The results of the simple regression equation: effect of athletic perfectionism on athletic performance

\begin{tabular}{|l|l|l|l|l|l|l|}
\hline \multirow{2}{*}{\multicolumn{2}{|l|}{ Model }} & \multicolumn{2}{|l|}{ Unstandardized Coefficients } & Standardized Coefficients & \multirow{2}{*}{ t } & \multirow{2}{*}{ Sig. } \\
\cline { 3 - 8 } & B & Std. Error & Beta & & \\
\hline \multirow{2}{*}{1} & (Constant) & 55.75 & 7.21 & & 7.72 & 0.001 \\
\cline { 2 - 7 } & Athletic perfectionism & 0.36 & 0.05 & 0.46 & 7.15 & 0.001 \\
\hline
\end{tabular}

According to the results of Table 5 and considering the significant test error level for the confidence level of 0.95 , it can be said that athletic perfectionism has a significant positive 
effect on athletic performance. The beta coefficient also shows that athletic perfectionism predicts 0.46 of the changes in athletic performance.

\section{Discussion}

The athletic performance of student athletes is influenced by various psychological factors, which has been confirmed by studies in this field. Considering the importance of athletic performance and the effect of sports psychological variables, the present study was conducted to investigate the role of athletic self-efficacy and athletic perfectionism in predicting athletic performance of Gazi University student athletes.

The results of the study show that athletic self-efficacy has a significant positive effect on athletic performance. Based on the beta coefficient of athletic self-efficacy, it predicts 0.54 of the changes in athletic performance. The research findings are consistent with the findings of Vegard et al. (2018). In their study, they concluded that self-efficacy has a significant impact on the athletic performance of professional ski jumpers. Also, the results of the study conducted by Sivrikaya (2019) show that self-efficacy has an influence on the athletic performance of football players, in other words, self-efficacy is one of the most important characteristics of a successful athlete.

In addition, Mouloud and Elkader (2016) showed that there is a positive and significant correlation between self-efficacy and the components of athletic performance and success in football players. However, these statements do not confirm the findings of Rasmusen (2016). This is because he concluded in his research that there is no relationship between self-efficacy and athletic performance.

To further explain the above findings, the importance of athletic self-efficacy must first be addressed. Some consider self-efficacy to be the most important psychological structure contributing to athletic performance. It is very important to consider the effects of self-efficacy on athletic performance because the numerous studies mentioned above have shown that self-efficacy is positively related to athletic performance, which means that people with higher self-efficacy are more able to cope with problems that occur during athletic competition.

Valiante and Morris (2013) studies supported Bandura's claims about dominance experiences as an important source of self-efficacy. They asked players to describe their careers, including their successes and failures, and how those successes and failures influenced their thought patterns, expected outcomes, and emotional states. They found that professional golfers are able to maintain high performance over a long period of time by remembering their previous successes. This is important because these athletes report that their belief in self-efficacy leads to a mindset that allows them to be calmer and more productive than they would otherwise be, and they perform better as a result.

It also shows that just being strong and physically healthy is not enough for an athlete to perform at their maximum. In addition to fitness and health, the theory of self-efficacy predicts that athletes will gain confidence in performing the required tasks. For example, two weightlifters with the same physical strength may not perform the same if they have different 
beliefs about their ability to lift weights (weightlifting self-efficacy); or two runners with the same speed may reach the finish line at different distances if they have different athletic self-efficacy.

The results of the study also show that athletic perfectionism has a significant positive effect on athletic performance and predicts 0.46 of changes in athletic performance. The findings of the study are in line with the findings of Madigan et al. (2018) who concluded that perfectionism improves athletic performance. Also, Jowett et al. (2016) showed in their study that self-efficacy as a psychological factor has an important influence on improving athletic performance. The research findings are consistent with the findings of Pourjavid (2015) who showed that positive perfectionism has a significant relationship with athletic performance of students. The research findings are also consistent with the findings of Byrd (2011), Gotwals et al. (2012), Stoeber (2012), Brandy et al. (2013) and Hill et al. (2014). In the aforementioned studies, the effect of self-efficacy on athletic performance was investigated and confirmed.

To explain the above results, it should first be said that perfectionism has been studied for many years. Early theoretical work focused on the relationship between perfectionism and psychological pathology (Hollender, 1965). Opinions on performance have diverged. Many theorists have argued that perfectionism is likely to impair performance. This was, of course, because it considered the cognitions, emotions, and disabling behaviors that form the basis of psychological pathology. However, further studies have shown that perfectionism can contribute to better performance in some cases, even if it comes at a higher cost. This is due to its potentially motivational or energizing properties, particularly sacrifice, determination, and perseverance, which can lead to obsessive commitment to activities in sport.

In general, a review of recent studies on perfectionism and performance in sport indicates that perfectionism is an important feature in the domains of progress in sport and performance, and that perfectionist efforts are interrelated in certain contexts. While there is evidence that perfectionistic endeavors may affect athletic performance, there is also ample evidence that they may play a more complex role in performance, which supports the findings of the present study. Therefore, it can be said that athletic perfectionism increases an individual's positive perception of support and social evaluations through realism, acceptance of personal limitations, and improving feelings of satisfaction and contentment with one's performance, and this process improves athletic performance and increases athletic success.

\section{Conclusion}

Based on the results of the study, it can be said that athletic self-efficacy and athletic perfectionism play a significant role in predicting the athletic performance of athletic students at Gazi University. Thus, with the increase of athletic self-efficacy and athletic perfectionism, the athletic performance of student athletes also increases. Accordingly, in addition to the physical and technical conditions of the players, the coaches and managers of university sports are recommended to pay attention to the psychological and personal characteristics of the players, especially the indicators of perfectionism and athletic self-efficacy of individuals. Based on the results of the study, it can be said that athletic self-efficacy and athletic 
perfectionism play a significant role in predicting the athletic performance of athletic students at Gazi University. Thus, with the increase of athletic self-efficacy and athletic perfectionism, the athletic performance of student athletes also increases. Accordingly, in addition to the physical and technical conditions of the players, the coaches and managers of university sports are recommended to pay attention to the psychological and personal characteristics of the players, especially the indicators of perfectionism and athletic self-efficacy of individuals. In addition, student athletes are recommended to adjust their training goals and plans in consultation with their teams' coaches and psychological advisors based on their self-efficacy and athletic perfectionism in order to achieve the highest level of athletic performance in the shortest time possible.

\section{References}

Brandy, M. C., \& Terry, F. P. II. (2013). Meeting High Standards: The Effect of Perfectionism on Task Performance, Self-esteem, and Self-efficacy in College Students. Psychology and Behavioral Sciences, 2(3), 117-123. https://doi.org/10.11648/j.pbs.20130203.16

Byrd, M. (2011). Perfectionism hurts: Examining the relationship between perfectionism, anger, anxiety and sport aggression (Submitted to the Faculty of Miami University in partial fulfillment of the requirements for the degree of Master of Science, Department of Kinesiology and Health).

Charbonneau, D., Barling, J., \& Kelloway, E. K. (2001). Transformational leadership and sports performance,the mediating role of intrinsic motivation. Journal of Applied Social Psychology, 31(7), 1521-1534. https://doi.org/10.1111/j.1559-1816.2001.tb02686.x

Dunn, J. G. H., Dunn, J. C., Gotwals, J. K., Vallance, J. K. H., Craft, J. M., \& Syrotuik, D. G. (2006). Establishing construct validity evidence for the Sport Multidimensional Perfectionism Scale. Psychology of Sport and Exercise, 7, 57-79. https://doi.org/10.1016/j.psychsport.2005. 04.003

Gallucci, N. T. (2008). Sport psychology: Performance enhancement, performance inhibition, individuals and teams. New York: Psychology Press.

Gotwals, J. K., Stoeber, J., Dunn, J. G. H., \& Stoll, O. (2012). Are perfectionistic strivings in sport adaptive? A systematic review of confirmatory, contradictory, and mixed evidence. Canadian Psychology, 53(4), 263-279. https://doi.org/10.1037/a0030288

Hill, A. P., \& Madigan, D. J. (2017). A short review of perfectionism in sport, dance and exercise: out with the old, in with the $2 \times 2$. Current Opinion in Psychology, 16, 72-77. https://doi.org/10.1016/j.copsyc.2017.04.021

Hill, A. P., Stoeber, J., Brown, A., \& Appleton, P. R. (2014). Team perfectionism and team performance: A prospective study. Journal of Sport \& Exercise Psychology, 36, 303-315. https://doi.org/10.1123/jsep.2013-0206

Hollender, M. H. (1965). Perfectionism. Comprehensive Psychiatry, 6, 94-103. https://doi.org/10.1016/S0010-440X(65)80016-5 
Jowett, G. E., Mallinson, S. H., \& Hill, A. P. (2016). An Independent Effects Approach to Perfectionism in Sport, Dance, and Exercise. In A. P. Hill (Ed.), The Psychology of Perfectionism in Sport, Dance, and Exercise (pp. 85-149). London: Routledge.

Madigan, D. J., Hill, A. P., Mallinson-Howard, S. H., Curran, T., \& Jowett, G. E. (2018). Perfectionism and performance in sport, education, and the workplace. Oxford Research Encyclopaedia of Psychology. Oxford University Press. https://doi.org/10.1093/acrefore/ 9780190236557.013 .166

Madigan, D., J, Stoeber, J., \& Passfield, L. (2016). Athletes perfectionism and reasons for training: perfectionism concerns predict training for weight control. Personality and Individual Differences. Oxford Research Encyclopaedia of Psychology. Oxford University Press. https://doi.org/10.1016/j.paid.2016.03.034

Mouloud, K., \& Elkader, B. (2016). Self-efficacy and Achievement Motivation among Football Player. The Swedish Journal of Scientific Research, 3(11), 13-19.

Newland, A., Newton, M., Finch, L., Harbke, C. R., \& Podlog, L. (2013). Moderating variables in the relationship between mental toughness and performance in basketball. Journal of Sport and Health Science, 2(3), 184-192.https://doi.org/10.1016/j.jshs.2012.09.002

Pourjavid (2015). Relationship between positive perfectionism, happiness and students' perceived athletic performance (Master Thesis in Sports Management, Faculty of Physical Education and Sports Sciences, Shahroud University of Technology).

Rasmusen, R. (2016). Tackling the Relationship between Self-efficacy and Performance in Rugby (A dissertation submitted in partial fulfilment of the requirements for the Degree of Master of Science in Applied Psychology at the University of Canterbury by Anthony).

Roberts, D. (2001). Coping Strategies of Runners: Perceived Effectiveness and Match to Pre-competitive Anxiety. J Sport Behav., 24, 144-61.

Rostamzadeh, F., \& Zehsaz, F. (2020). Investigation of the relationship between PGC-1 $\alpha$ gene polymorphism and athletic performance in non-athlete boys. Koomesh Journal, 22(3), 492-496. https://doi.org/10.29252/koomesh.22.3.492

Sahraian, F., Waez, M., Seyed, M. K., \& Khabiri, M. (2016). Introduction to athletic Self-efficacy Questionnaire. Sports Psychology Studies, 16, 57-70.

Sivrikaya, H. (2019). The Role of Self-efficacy on Performance of Sports Skills of Football Players. Journal of Education and Training Studies, 6(12), 79-75. https://doi.org/10.11114/ jets.v6i12a.3952

Stoeber, J. (2012). Perfectionism and performance. In S. M. Murphy (Ed.), Oxford handbook of sport and performance psychology (pp. 294-306). New York: Oxford University Press. https://doi.org/10.1093/oxfordhb/9780199731763.013.0015

Stoeber, J. (2014). Perfectionism. In R. C. Eklund \& G. Tenenbaum (Eds.), Encyclopedia of sport and exercise psychology (Chap. 2, pp. 527-530). 


\section{Macrothink}

Journal of Educational Issues

ISSN 2377-2263

2021, Vol. 7, No. 2

Valiante, G., \& Morris, D. B. (2013). The sources and maintenance of professional golfers' self-efficacy beliefs. Sport Psychologist, 27, 130-142. https://doi.org/10.1123/tsp.27.2.130

Vegard, H. S., Håvard, W. L., \& Hermundur, S. (2018). Self-efficacy, Flow, Affect, Worry and Performance in Elite World Cup Ski Jumping. Journal of Front Psychol, 9, 1-9. https://doi.org/10.3389/fpsyg.2018.01215

\section{Copyright Disclaimer}

Copyright for this article is retained by the author(s), with first publication rights granted to the journal.

This is an open-access article distributed under the terms and conditions of the Creative Commons Attribution license (http://creativecommons.org/licenses/by/3.0/). 